\title{
Analysis and Reviews on Tourism and Travel Mobile Apps of China
}

\author{
Zhiyang $\mathrm{Jia}^{1, \mathrm{a}^{*}}$, Ding $\mathrm{Li}^{1, \mathrm{~b}}$ and Fengzhen $\mathrm{He}^{1, \mathrm{c}}$ \\ ${ }^{1}$ Tourism and Culture College of Yunnan University, Lijiang, China \\ ajdyjazz@gmail.com, ’dingli.ynu@gmail.com, chefengzhen@ynu.edu.cn \\ ${ }^{*}$ Corresponding author
}

Keywords: Tourism app; Travel app; Chinese mobile app; Analysis and review

\begin{abstract}
Mobile applications have become one of the primary ways people communicate, shop, organize their lives, play, and even work. About $40 \%$ of the world's Android users are in China. There are many kinds of tourism and travel related app both available in the Apple App Store and various Android app stores in China. According to the download times in 2015, the top ten popular tourism and travel apps in China are Ctrip, Qunar, Tongcheng, Didi, Tuniu, Kuaidi, Elong etc. According to the statistics and existing circumstances of tourist apps, a comprehensive analysis of tourism and travel mobile apps is presented, including industry map of tourism and travel apps, market share of flight booking business, major business comparisons. Summary and prospect of mobile tourism are presented.
\end{abstract}

\section{Introduction}

China is a huge driver of growth when it comes to worldwide smartphone adoption and, despite low penetration overall, it already boasts the largest smartphone subscriber base in the world [1]. The number of Chinese outbound tourists reached 107 million person trips in 2014 [2]. More and more travelers tend to travel abroad during the holidays. The total number of China's tourists is estimated to exceed 4.1 billion person trips in 2015. The rapid growth of mobile internet consumption has led consumers transferring from the PC client to the mobile client. Since January 2015 [3], the number of active users on mobile apps has surpassed that of the PC side, and the gap is gradually increasing. The young generations are used to booking travel products on mobile apps.

More than five years after the launch of Apple's App Store, mobile applications have become one of the primary ways people communicate, shop, organize their lives, play, and even work. A mobile app is a computer program designed to run on mobile devices such as smartphones and tablet computers [4]. Most such devices are sold with several apps bundled as pre-installed software, such as a web browser, email client, calendar, mapping program, and an app for buying music or other media or more apps. Mobile marketing provides a huge opportunity for marketers to engage with customers and prospects anytime, anywhere. This ability for marketers to be "constantly connected" has been made possible largely due to the emergence of mobile applications.

With the new wave of smartphones and the various app stores, phone manufacturers have once redefined our expectations of what can be expected of a mobile phone. What was previously an elusive promise of technology convergence has become a game-changing reality and, for the tourism industry, this represents an unprecedented opportunity to deliver destination visitor information and to provide booking service. As the logical extension to peoples' work on e-tourism solutions and visitor web sites, the tourism specific apps that we have developed in the past are now proving to be best practice examples of how to deliver detailed tourism information to the visitor when in-location. As well as being powered from a sophisticated structured database, the apps are available for both the iPhone and Android operating systems. After downloading the tourism and travel apps, users simply touch the icon to access a rich, interactive guide to the tourism offer. Using the geo-location of the phone (GPS) [5], the users are able to see where they are in relation to all the attractions, restaurants and events around them. Also they can book tickets of trains, air-plans and High-speed rails. All the 
content is delivered to the app directly from our product management database and is presented in beautiful scrolling pages of imagery and content.

\section{Overview of Tourism and Travel Mobile Apps in China}

About $40 \%$ of the world's Android users are in China [6]. It's estimated there are now more than 200 app stores in China. Including Baidu, Alibaba and Tencent giants to phone carriers and smart phone developers, almost all the big companies in China want to create their own ecosystem through individual app stores. Table 1 has listed the top ten poplar Android app stores in China.

\section{Table 1. Top ten popular Android app stores in China}

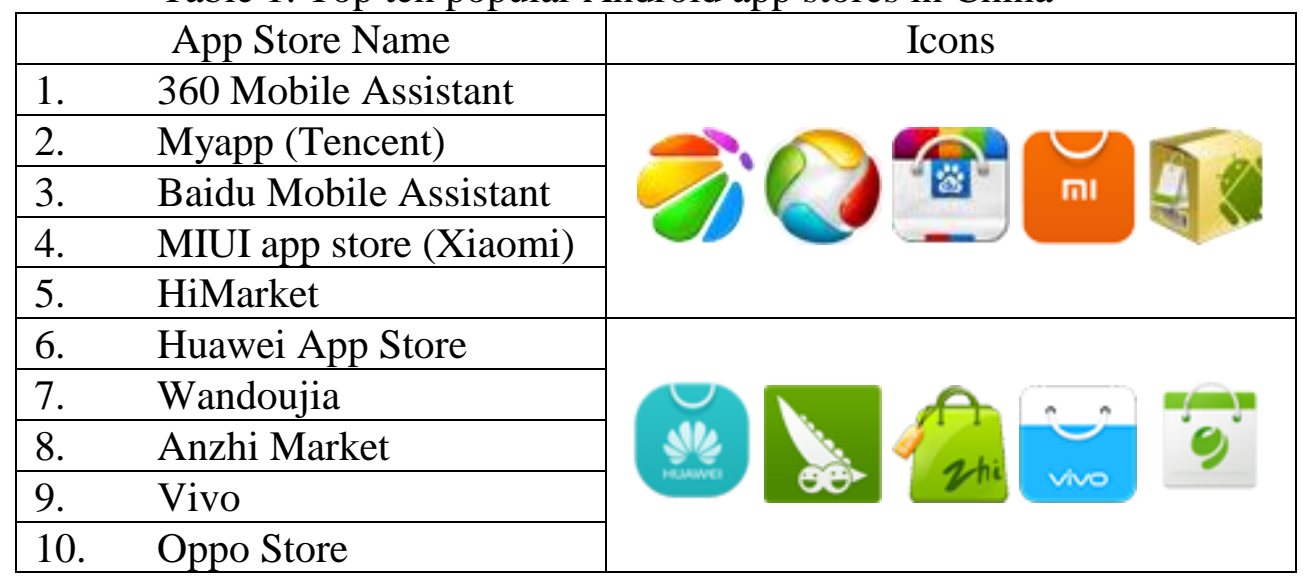

There are many kinds of tourism and travel related app both available in the Apple App Store and various Android app stores. According to the download times in 2015, top ten popular tourism and travel apps in China are counted in Fig. 1.

\section{Download ( million times)}

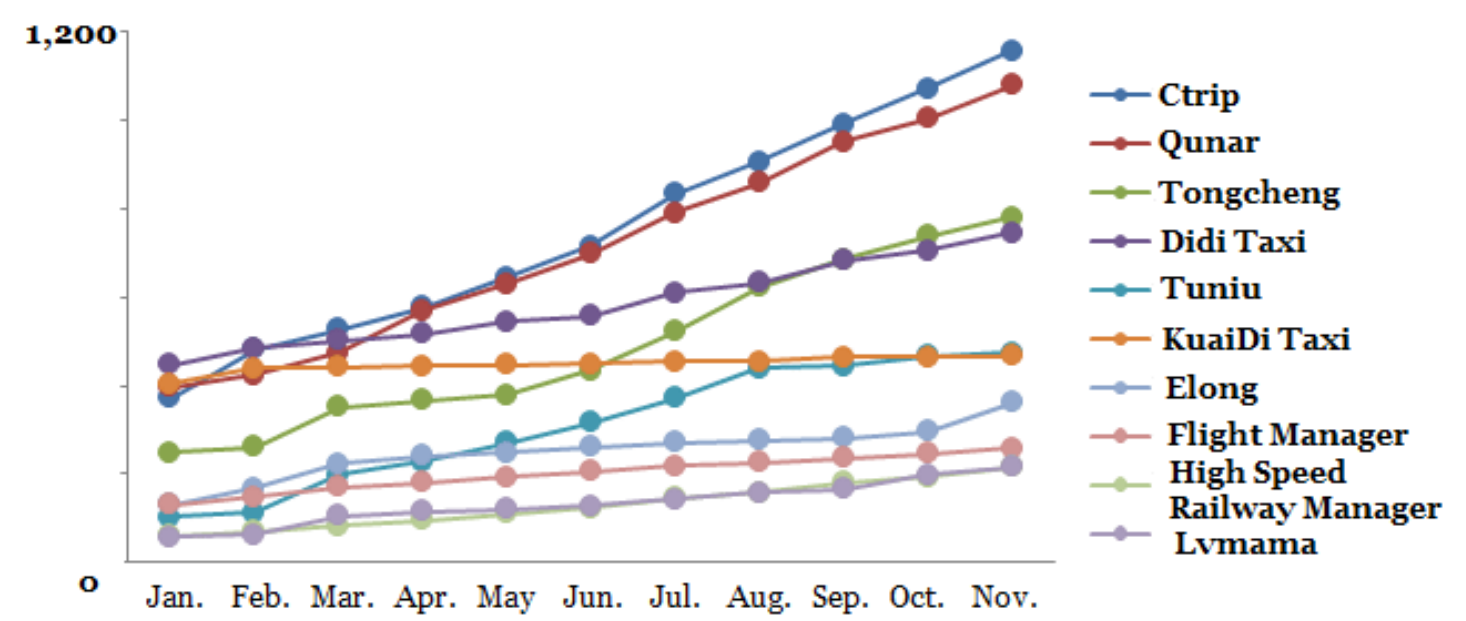

Figure 1. Top ten popular (based on download times) tourism and travel apps in China

Industry map of tourism and travel apps can be demonstrated as Fig. 1. 


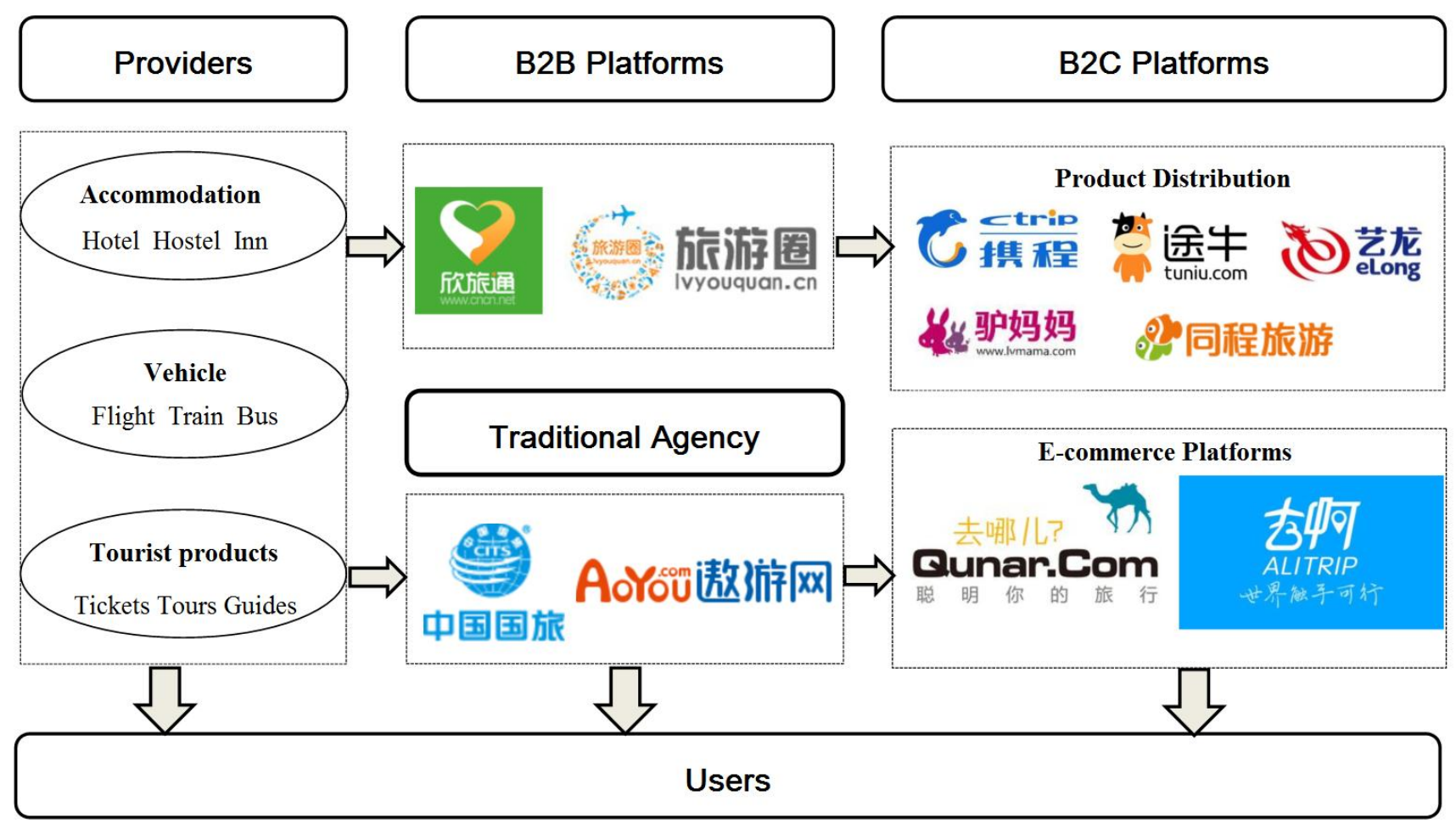

Figure 2. Industry map of tourism and travel apps in China

\section{Comprehensive Analysis of Tourism and Travel Mobile Apps}

Take the case of major business, comparisons of Ctrip, Qunar, Tongcheng, Tuniu, Elong and Lvmama are demonstrated in Table 1.

Besides, GPS navigation and map guidance is no doubt the most important feature of mobile travel apps. Almost all of the apps have provided this feature. And photos sharing and travel records that are supported by the apps have a great attraction to the tourists. Offline guided tour is a very useful function for both outbound and domestic tourists.

Because the traditional OTA provides travel routes, attractions tickets, travel and vacation products in the mobile phone client, it is compatibility issue that how to present products in mobile phone client as well as PC client.

User interface of apps needs to be improved. It is very hard to show much content in a four inch or smaller mobile phone screen, so the user's experience is essential. It is easy to find that many app interfaces is too complex, navigation is not clear, which gives the user's use has brought great inconvenience.

Table 2. Major business comparisons of tourism apps

\begin{tabular}{|c|l|l|l|l|l|}
\hline & Hotel booking & Fight Tickets & Tour booking & \multicolumn{1}{|c|}{ Guided } & \multicolumn{1}{|c|}{ Specialty } \\
\hline Ctrip & Yes & Yes & Yes & Yes & $\begin{array}{l}\text { Big amount } \\
\text { of hotels }\end{array}$ \\
\hline Qunar & Yes & Yes & Yes & Yes & $\begin{array}{l}\text { Flight price } \\
\text { parity }\end{array}$ \\
\hline Tongcheng & Yes & Yes & Yes & Yes & B2B \& B2C \\
\hline Tuniu & Yes & Yes & Yes & Yes & UGC \\
\hline Elong & Yes & Yes & Yes & Yes & Self-run tours \\
\hline Lvmama & Yes & Yes & Yes & Yes & UGC \\
\hline
\end{tabular}

Ctrip accommodation reservation and ticket booking services maintained robust growth, reaching $69 \%$ and $98 \%$ year-over-year in volume respectively. As shown in the Fig. 1 Ctrip and Qunar were 
ranked first and second in the 2015, both APP has maintained rapid growth. The conversion rates of users, according to data disclosed by the two companies, accounting from the mobile terminal has been increasing steadily, especially during the holidays. The mobile end user is an important channel for the online reservation. According to data disclosure by Ctrip in the third quarter of 2015, Ctrip order amount of tourist products online booked by mobile terminals grew up to $400 \%$. At the end of the near "double eleven" promotion battle, Ctrip mobile terminal reservation ratio of more than $60 \%$, PC end only 40\%, compared with last year the ratio reversed trend is clearly acceding.

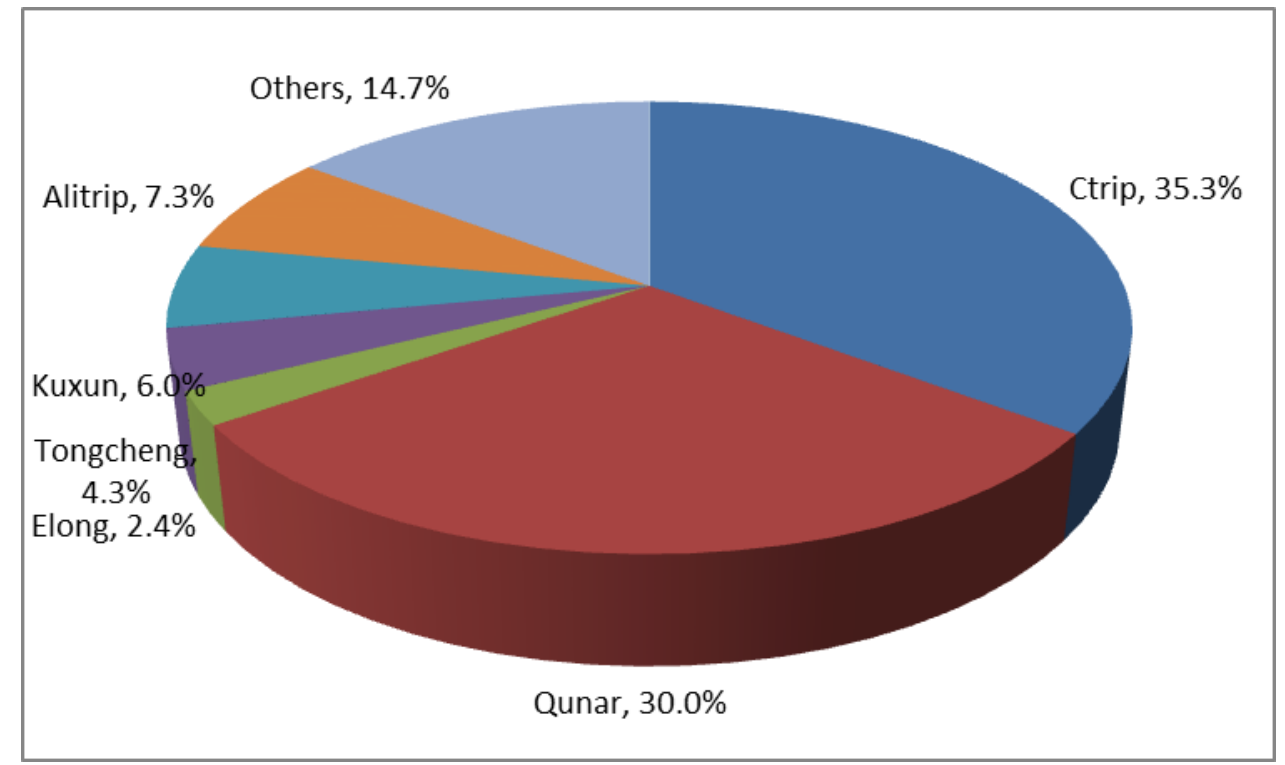

Figure 3. Market share of flight booking business

Ctrip is an online tourism agent, which directly interacts with both suppliers and users. Qunar, in contrast, is a platform with a majority of its income coming from advertisements. However, as Ctrip opened up to third-party service providers and Qunar began to transform into an OTA, the distinction between the two companies became blurred. Data shows that in the market shares of China Online Tourism Agent (OTA), Ctrip accounted for 54.2\%, while Elong and Tongcheng seized $8.7 \%$ and $6.1 \%$ respectively. The three OTA giants captured almost $70 \%$ of market shares in total. Mobile bookings comprised approximately 55\% of eLong brand room nights, excluding room nights from non-eLong brand distribution partners and resellers, and the cumulative downloads of eLong mobile apps ranking the $7^{\text {th }}$. Domestic hotel coverage network of eLong expanded $186 \%$ to over 200,000 domestic hotels. Ctrip unceasingly optimizes its current products and improve the industrial chain of tourism (frequently purchased tourism companies of other fields) so that it can keep a competitive position among OTA players. Tongcheng joined the cooperation with Ctrip after terminating its cooperation with Elong, and finally got support from Ctrip on payment at scenic spots. Besides, Tongcheng and Ctrip can get complementary benefits because they have developed different client groups and have got advantage in different fields. As for Elong, its online hotel booking service will be shocked by core OTA and it will face greater threat from cooperation of Ctrip and Tongcheng. The statistics of market share of flight booking business is depicted in Fig. 1.

The travel guide app helps travelers make their travel plan in destinations. The top 3 travel guide mobile apps in China were Tuniu travel guide, Mafengwo, and Qyer guide. As shown in Fig. 1, Tuniu ranking the $5^{\text {th }}$ in the total tourism mobile market. Although Mafengwo and Qyer are not rangking in the top 10 popular apps, they are viewed as the most popular tourism UGC (User Generated Content) apps. 


\section{Summary}

Online travel market competition is becoming increasingly fierce, the diversification of consumer demand is also growing, online travel market segmentation, and product line diversification has become a trend. Chinese online traveling service provider Ctrip finally merged with Qunar in October 2015 [6], a relatively newcomer compared to Ctrip. Ctrip as the leading force is actually gaining momentum still. Ctrip first acquired eLong and then invested in Tuniu and Tongcheng. After integrating Qunar into its system, Ctrip's market share of the OTA sector has jumped to more than $71.5 \%$.

With the popularity of the change of people's travel mode and intelligent applications and development of online travel market is becoming localization, in addition to the long-distance traffic between the source and destination. To meet consumer demand for local users to travel in the catering, entertainment, transportation and ticketing service life, and service in the global tourism market transactions accounted for about $50 \%$ of the market, only $10 \%$ in China, there is a larger space for further development.

With the fantastic spur both in industry and in economy in China, the number of online tourism service user is on the rise. On the one hand is explosive growth for mobile tourism market. Another is online travel service platform using mobile apps to make full use of the advantage of Internet. With the popularity of tourism apps, it makes personal travel more convenient. Integration with online payment solutions and security measures also make mobile phone users used to mobile tourist life.

\section{References}

[1] Lee, Chunghun, Nayeon Kwak, and Choong Lee, Understanding Consumer Churning Behaviors in Mobile Telecommunication Service Industry: Cross-national Comparison between Korea and China. (2015).

[2] Wang, Yue, and Pauline J. Sheldon, The sleeping dragon awakes: The outbound Chinese travel market. Journal of Travel \& Tourism Marketing 4.4 (1996): 41-54.

[3] Jia, Zhiyang, Ding Li, and Wei Gao, Evaluation of Chinese Online Tourism and Travel Service Providers from the Users' Perspective. 2015 International Conference on Management, Education, Information and Control. Atlantis Press, 2015.

[4] Gibbs C, Gretzel U, Drivers of Responsive Website Design Innovation by Destination Marketing Organizations[M]//Information and Communication Technologies in Tourism 2015. Springer International Publishing, 2015: 581-592.

[5] Blaser, Monica K. "Opportunities of an Interpretive Application for Self-guided Tourism within the National Park System." (2015).

[6] Information on http://www. beijingtoday.com.cn 